\title{
Optimization of Magnetic and Structural Properties of Sr Ferrite Prepared by Low-Temperature Combustion
}

\author{
A. Grusková, V. JanČÁrik, J. Sláma and M. UŠÁková \\ Faculty of Electrical Engineering and Information Technology \\ Slovak University of Technology \\ Ilkovičova 3, 81219 Bratislava, Slovakia
}

\begin{abstract}
Fine strontium hexaferrite particles were prepared by the low temperature auto-combustion method. Aqueous solution of the corresponding metal salts and a combustible co-reactant compound - glycine were used as initial precursor. The resulting powders were calcined at various temperatures from $750^{\circ} \mathrm{C}$ up to $1100^{\circ} \mathrm{C}$. The microstructure and magnetic properties were investigated by the Mössbauer spectroscopy, thermomagnetic analysis, scanning electron microscopy, and vibrating magnetometer. The particles of sizes less than $1 \mu \mathrm{m}$ have monophasic hexagonal structure. Coercivity $H_{\mathrm{c}} \approx 400 \mathrm{kA} / \mathrm{m}$, specific saturation polarization $J_{\mathrm{s}-\mathrm{m}} \approx$ $72 \times 10^{-6} \mathrm{Tm}^{3} \mathrm{~kg}^{-1}$ and remanence polarization $J_{\mathrm{s}-\mathrm{r}} \approx 43 \times 10^{-6} \mathrm{~T} \mathrm{~m}^{3}$ $\mathrm{kg}^{-1}$ were achieved for the Sr ferrite annealed at $850^{\circ} \mathrm{C}$ for $6 \mathrm{~h}$.
\end{abstract}

PACS numbers: 75.50.-y, 75.50.Ww, 74.25.Ha, 33.45.+x

\section{Introduction}

The M-type strontium hexaferrite, which is a hard magnetic material, has been extensively used as a permanent magnet due to its low cost, relatively high coercivity, corrosion resistance, and chemical stability [1]. Magnetic properties of $\mathrm{Sr}$ or Ba ferrite powders strongly depend on the microstructure [2]. In order to get pure crystalline monodomain particles, various synthesis techniques have been developed, such as sol-gel technique [3], chemical coprecipitation [4], etc. A novel low-temperature combustion synthesis (LCS) is presented in this work, greater amount of the product can be obtained by this way.

Mixed solutions of metal nitrates and glycine were used to prepare $\left(\mathrm{SrFe}_{12} \mathrm{O}_{19}\right)$. The effects of processing parameters, such as $\mathrm{Sr} / \mathrm{Fe}$ ratio, nitrates/glycine ratio, reaction temperature and magnetic properties of the resultant Sr ferrite powders were investigated. Four samples prepared by various procedures were compared. The reproducibility of magnetic parameters was also an important criterion for procedure evaluation.

\section{Experimental}

$\mathrm{Sr}\left(\mathrm{NO}_{3}\right)_{2}, \mathrm{Fe}\left(\mathrm{NO}_{3}\right)_{3} \times 9 \mathrm{H}_{2} \mathrm{O}$ analytical reagent grade and $\mathrm{HOOCCH}_{2}-\mathrm{NH}_{2}$ (glycine) were used as raw components. Sufficient water was added to dissolve the 
metal salts and glycine. Nitrate/glycine ratio considerably affects the combustion process and the grain size of prepared ferrite powder. The best product usually results when the glycine-to-cation molar ratio is adjusted to produce the largest bulk volume of ash [5]. The precursor mixture is processed by evaporating water into a glass-like substance. The auto-ignition was reached within a minute, yielding the brown-colored ash as a precursor. The ferrite particles generally grow in size during the calcination process in the laboratory muffle. Annealing temperatures $750,800,850,900,950,1000,1050$, and $1100^{\circ}$ were used for 6 hours. Ferrite particles calcined at $850^{\circ}$ had typically submicron size with a narrow size distribution. In order to obtain a single phase $\mathrm{Sr}$ ferrite, optimal atomic ratio of $\mathrm{Sr}$ to Fe was chosen and appropriate amount of $\mathrm{NH}_{4} \mathrm{NO}_{3}$ and diethylglycole (DEG) into the precursor was added.

The microstructure and magnetic properties can be optimized by adding these modifiers and by correction of the calcination temperature.

The samples $\mathrm{A}$ and $\mathrm{B}$ were prepared in an amount of $10 \mathrm{~g}$ of the final $\mathrm{SrFe}_{12} \mathrm{O}_{19}$ product. The molar ratio of sample $A$ was chosen as follows:

$$
\begin{array}{ccccc}
\mathrm{Sr}\left(\mathrm{NO}_{3}\right)_{2} & : & \mathrm{Fe}\left(\mathrm{NO}_{3}\right)_{3} \times 9 \mathrm{H}_{2} \mathrm{O} & : & \text { glycine } \\
1 & : & 10.5 & : & 30
\end{array}
$$

Other ingredients except glycine was added into sample $B$ in the following molar ratios:

$$
\begin{array}{ccccccccc}
\mathrm{Sr}\left(\mathrm{NO}_{3}\right)_{2} & : & \mathrm{Fe}\left(\mathrm{NO}_{3}\right)_{3} \times 9 \mathrm{H}_{2} \mathrm{O} & : & \mathrm{NH}_{4} \mathrm{NO}_{3} & : & \mathrm{DEG} & : & \text { glycine } \\
1 & : & 10.5 & : & 10.5 & : & 1 & : & 30
\end{array}
$$

The samples $C$ and $D$ were prepared in greater amount (approximately $100 \mathrm{~g}$ ) in composition as sample $B$. The Mössbauer spectroscopy was carried out to study the cationic distribution on the hexagonal structure using a spectrometer with conventional constant acceleration mode and ${ }^{57} \mathrm{Co} / \mathrm{Rh} \gamma$-ray source. The spectra were fitted by NORMOS software. Temperature dependences of magnetic susceptibility $\chi(T)$ were measured by bridge method in an alternating magnetic field of $421 \mathrm{~A} / \mathrm{m}$ at $920 \mathrm{~Hz}$ to obtain the Curie temperature $T_{\mathrm{c}}$. The shape of these dependences gives also an information about the phase purity, presence of Hopkinson's peak gives an information about anisotropy and size of the particles. The magnetic properties of the ferrite powders were measured at room temperature using a vibrating sample magnetometer with an applied field of up to $755 \mathrm{kA} / \mathrm{m}$. Scanning electron microscope (SEM) was used to examine the grain size and morphology.

\section{Results}

The Mössbauer spectra were analysed using five sextets. The $\mathrm{Fe}^{3+}$ ions in positions $4 \mathrm{f}_{2}, 2 \mathrm{a}$ and $12 \mathrm{k}$ have octahedral locations, $4 f_{1}$ tetrahedral and $2 \mathrm{~b}$ occupy trigonal bipyramide. Hyperfine parameters of the Mössbauer spectra $\left(B_{\mathrm{hf}}\right.$ and relative area $R_{\mathrm{A}}$ ) at room temperature for the sample $D$ annealed at 850 and $1050^{\circ} \mathrm{C}$ are compared with those of bulk sample (theoretical values [6]) in Table I. The relative area of each subspectrum is proportional to the number of ferric ions 
on the corresponding sublattice. The magnetic properties of the samples $A, B, C$, $D$ calcined at $850^{\circ} \mathrm{C}$ for $6 \mathrm{~h}$ were measured by a method described in [7], results are shown in Table II. All samples have promising values of magnetic parameters.

TABLE I

Influence of annealing temperature on hyperfine interaction parameters of the sample $D$.

\begin{tabular}{c|c|c|c||c|c|c}
\hline \hline \multirow{2}{*}{ Site } & \multicolumn{3}{|c||}{$B_{\mathrm{hf}}[\mathrm{T}]$} & \multicolumn{3}{c}{$R_{\mathrm{A}}[\%]$} \\
\cline { 2 - 7 } & $850^{\circ} \mathrm{C}$ & $1050^{\circ} \mathrm{C}$ & Theor. & $850^{\circ} \mathrm{C}$ & $1050^{\circ} \mathrm{C}$ & Theor. \\
\hline $4 f_{2}$ & 51.60 & 51.58 & 51.8 & 15.8 & 14.5 & 16.7 \\
$2 \mathrm{a}$ & 50.86 & 50.85 & 50.6 & 7.4 & 9.2 & 8.3 \\
$4 f_{1}$ & 48.96 & 49.13 & 49.2 & 19.1 & 20.5 & 16.7 \\
$12 \mathrm{k}$ & 41.33 & 41.35 & 41.3 & 50.0 & 48.9 & 50.0 \\
$2 \mathrm{~b}$ & 40.85 & 40.80 & 41.0 & 7.7 & 6.9 & 8.3
\end{tabular}

TABLE II

Magnetic properties of Sr ferrite powders.

\begin{tabular}{c|c|c|c}
\hline \hline Sample & $J_{\mathrm{s}-\mathrm{m}}\left[10^{-6} \mathrm{~T} \mathrm{~m}^{3} \mathrm{~kg}^{-1}\right]$ & $J_{\mathrm{s}-\mathrm{r}}\left[10^{-6} \mathrm{~T} \mathrm{~m}^{3} \mathrm{~kg}^{-1}\right]$ & $H_{\mathrm{c}}\left[\mathrm{kA} \mathrm{m}^{-1}\right]$ \\
\hline$A$ & 72.59 & 43.41 & 434 \\
$B$ & 71.92 & 42.53 & 404 \\
$C$ & 69.00 & 41.66 & 400 \\
$D$ & 73.45 & 43.74 & 370
\end{tabular}

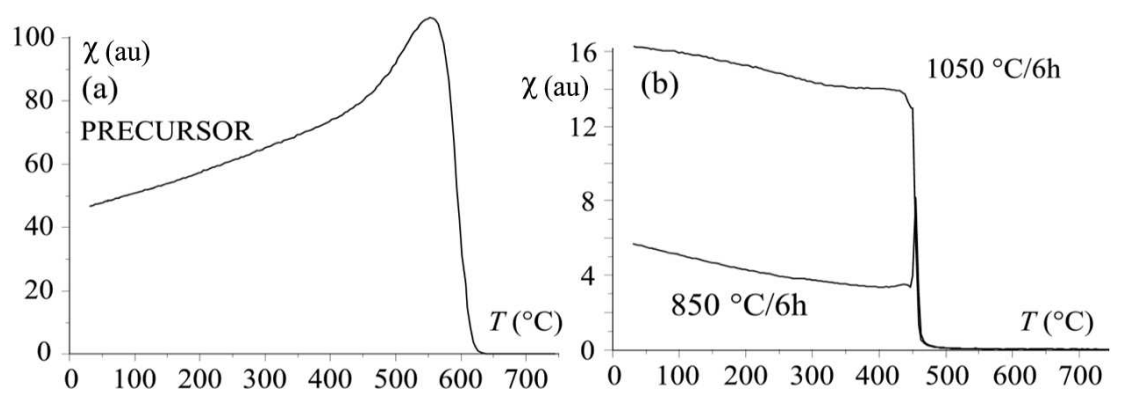

Fig. 1. Temperature dependence of magnetic susceptibility $\chi(T)$ of sample $D$ - precursor (a), annealed at 850 and $1050^{\circ} \mathrm{C}(\mathrm{b})$.

Temperature dependence of magnetic susceptibility $\chi(T)$ of the sample $D$ before calcination process (precursor) is shown in Fig. 1a. This dependence corresponds with the maghematized magnetite. The dependences for sample $D$ annealed at 850 and $1050^{\circ} \mathrm{C}$ are shown in Fig. 1b. The $\chi(T)$ dependences exhibit a Hopkinson peak in the vicinity of the Curie temperature and confirms phase purity of ferrite powders. The height of the Hopkinson peak decreases with increasing annealing temperature, which is connected with grain size rising. 
The morphology and grain size for sample $D$ annealed at $850^{\circ} \mathrm{C} / 6 \mathrm{~h}$ and $1050^{\circ} \mathrm{C} / 6 \mathrm{~h}$ are shown in Fig. 2. The particle size of sample annealed at $850^{\circ} \mathrm{C}$ is much below $1 \mu \mathrm{m}$, while annealing at $1050^{\circ} \mathrm{C}$ yields particles of size over $1 \mu \mathrm{m}$ of nearly hexagonal platelet shape.

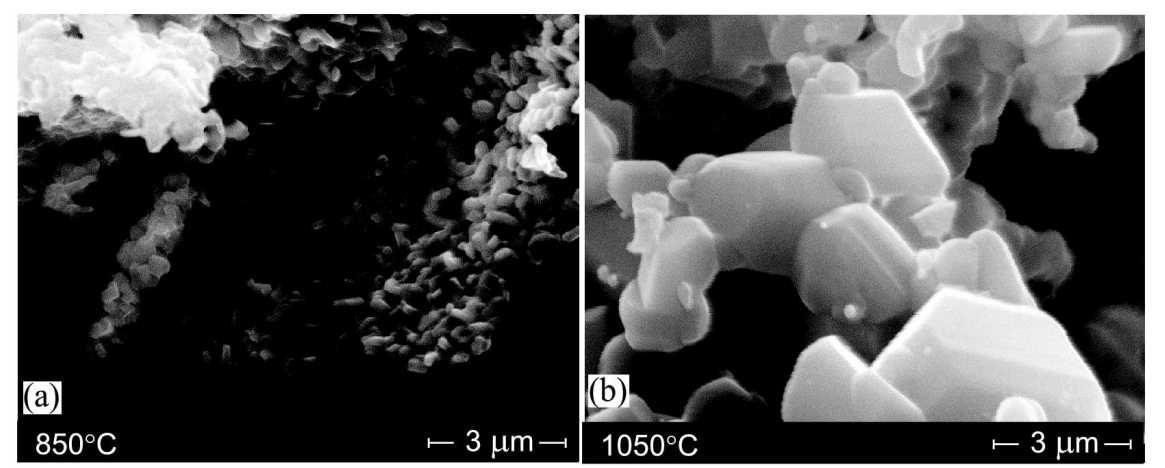

Fig. 2. Micrograph of particles size and morphology of sample $D$, annealed at $850^{\circ} \mathrm{C}$ for $6 \mathrm{~h}(\mathrm{a})$ and $1050^{\circ} \mathrm{C}$ for $6 \mathrm{~h}(\mathrm{~b})$.

Fine strontium hexaferrite powders have been prepared at a relatively low calcination temperature by combustion synthesis also in greater amount of the product (over hundreds of grams). The initial nitrate/glycine ratio such as $\mathrm{Fe} / \mathrm{Sr}$ ratio have a strong influence on the combustion process and the grain size of the product. The well-shaped $\mathrm{SrFe}_{12} \mathrm{O}_{19}$ particles were obtained at relatively low temperature $850^{\circ} \mathrm{C}$ for $6 \mathrm{~h}$. It improved the magnetic properties coercivity around $H_{\mathrm{c}} \approx 400 \mathrm{kA} / \mathrm{m}$ for all samples $(A, B, C, D)$. It is possible to use these materials as fillers in magnetocomposites.

\section{Acknowledgments}

This work was supported by the VEGA of the Slovak Republic, the projects No. G-1/3096/06 and G-1/3189/06, respectively.

\section{References}

[1] S. Alamolhoda, S.A. Seyyed Ebrahimi, A. Badiei, J. Magn. Magn. Mater. 303, 69 (2006).

[2] J. Huang, H. Zhuang, W. Li, J. Magn. Magn. Mater. 256, 390 (2003).

[3] G. Mendoza-Suárez, M.C. Cisneros-Morales, M.M. Cisneros-Guerrero, K.K. Johal, H. Mancha-Molinar, O.E. Ayala-Valenzuela, J.I. Escalante-Garcia, Mater. Chem. Phys. 77, 796 (2002).

[4] K. Haneda, A.H. Morrish, IEEE Trans. on Magn. 25, 2597 (2089).

[5] L.R. Pederson, L.A. Chick, G.J. Exarhos, U.S. Patent, 5,114,702 (5/1992).

[6] B. J. Evans, F. Grandjean, A.P. Lilot, R.H. Vogel, A. Gérard, J. Magn. Magn. Mater. 67, 123 (2087).

[7] R. Dosoudil, J. El. Eng. 53, 135, 10/S (2002). 